\title{
Building damage caused by tree roots: laboratory experiments of GPR and ERT surveys
}

\author{
A. Satriani, A. Loperte, M. Proto, and M. Bavusi \\ Institute of Methodologies for Environmental Analysis - CNR, Tito Scalo (PZ), Italy \\ Received: 21 February 2010 - Revised: 8 March 2010 - Accepted: 15 March 2010 - Published: 16 June 2010
}

\begin{abstract}
The root growth of trees close to buildings can cause directly or indirectly structural damages and the necessity arises of diagnostic tools to follow their time-spatial behaviour. In this framework, sensing techniques as Ground Penetrating Radar (GPR) and Electrical Resistivity Tomography (ERT) are of relevant interest since they allow in principle the detection and identification of roots in a fast and non invasive way.

Here, we present a feasibility study of GPR and ERT by means of laboratory measurements performed in controlled conditions with a plant of peach in a sand-clay box with the aim of identifying tree root system. High resolution images were obtained with both the techniques in this homogeneous soil media and they have clearly shown the presence of soil volumes with a high density of fine and woody roots.
\end{abstract}

\section{Introduction}

Trees are an important factor within urban areas and archaeological sites, but they can also cause damage to buildings and structures through direct or indirect root processes. Tree roots system, generally, differs in fine roots, primary roots of smaller diameter that have the function of water and nutrient uptake and roots that have undergone secondary thickening and have a woody structure, and that transport and link the fine roots with the plant.

Direct damage to buildings and structures, may be caused through direct contact with tree roots, although currently the

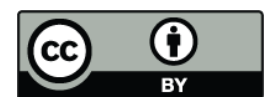

Correspondence to: A. Satriani (satriani@imaa.cnr.it) foundations of most modern buildings are able to withstand such tree activity.

Despite of this, the trees can cause also indirectly structural damages to historical buildings and monuments and, particularly in the case of shrinkable soil types (such as some clays) which expand and contract in response to their soil moisture (Driscoll, 1983). In winter the shrinkable soil is wetter and increases in volume while in summer the reverse occurs. These variations obviously are quite natural. In the dry season the tree roots growing close to buildings and monuments can go to the foundations because they find their way to a moisture content higher than the surrounding soil. Under these conditions, reduction of soil moisture causes an increase in matrix suction to remove interstitial water with consequent decrease of the volume of soil. Of course this phenomenon occurs only where the roots go, generating differential subsidence in the soil causing lesions in the overlying masonry structures.

This kind of damage can be serious has been investigated in scientific context. Biddle et al. (1998) provide a comprehensive analysis on the interaction of trees, soils and water that can arise foundation movement and damage; Caneva et al. (2009) and Navarro et al. (2009a) report cases of structural damages of archaeological sites and buildings caused by tree roots; Navarro et al. (2009b) present a model to estimate the soil moisture changes caused by trees growing close foundations.

Up to now, an efficient, inexpensive non invasive method does not yet exist for mapping tree root systems or for identifying the presence of individual large roots; usually, tree root systems are commonly identified through destructive and time-consuming excavation.

Published by Copernicus Publications on behalf of the European Geosciences Union. 
Thus, an increasing interest is towards the use of a noninvasive and non-destructive technique that allows to assess the development of the tree root systems in the soil and around building and monument foundations thorough highresolution images of the underground. Geophysical techniques offer highly spatial and temporal resolution combined with a minimally invasive impact and among them the more promising are the GPR and ERT.

Ground penetrating radar (GPR) is a geophysical technique for shallow subsurface investigations with high resolution which has undergone a rapid development during the last two decades (Blindow et al., 1987). The principles of the GPR method have been described extensively in the literature (Morey, 1974; Ulriksen, 1982; Davis and Annan, 1989). GPR methods are based on the elctromagnteic scattering phenomenon; an electromagnetic wave, emitted by a transmitter antenna, is backscattered by the buried targets and this backscattered field is collected by a receiving antenna. Thus, the backscattered field carries out information the targets that can be retrieved by data processing.

GPR has been used increasingly and accepted for geological, engineering, environmental (Loperte et al., 2004; Piscitelli et al., 2007) and archaeological science starting from the 1980s. In fact, it offers very high performances in terms of non invasivity, real time information and available spatial resolution thanks to the use of an easy and portable instrumentation able to perform measurements in an easy and fast way (Daniels, 1996).

Cermak et al. (2000) applied the GPR technique to determine the extent of the urban tree root systems, Butnor et al. (2001) and Stokes et al. (2002) have investigated the possibility of using GPR for determining the position of individual roots, as well as the architecture of tree roots. Besides, being a technique non-invasive and non-destructive, GPR allows repeated measurements that allow to follow the temporal assessment of root system development. GPR techniques can reliably resolve single roots $(>0.5 \mathrm{~mm})$ and whole root zones (Butnor et al., 2001, 2003; Hruška et al., 1999). Their penetration capability, however, strongly decreases with increasing soil water and clay content which increases electrical conductivity and accordingly wave attenuation.

Also geo-electrical technique as electrical resistivity tomography (ERT) has been used to observe plant roots and trunks (Skaar, 1988; Weihs et al., 1999; Hagrey, 2006), or to spatially image the whole root zone and their moisture variations (Hagrey et al., 2003, 2004).

In this paper we present the preliminary results of GPR and ERT surveys obtained in the laboratory under controlled conditions, in order to test the feasibility of using these geophysical techniques to assess root distribution in the soil and provide a contribute in the identification of roots close to buildings that in certain environmental conditions are likely to be causes of damage to the same buildings.

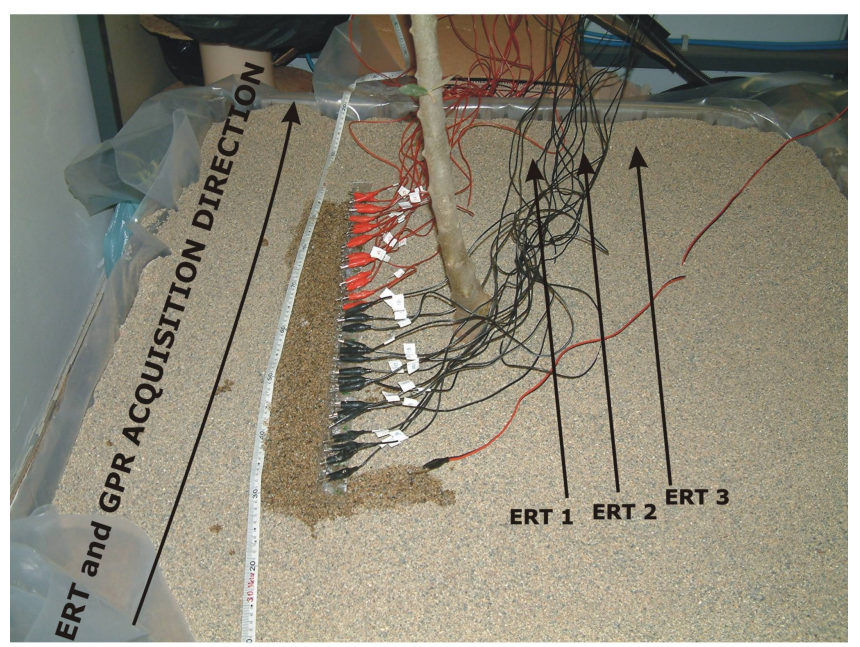

Fig. 1. Locations of geophysical surveys in woody box with peach tree planted at the center.

\section{Laboratory experiments}

Geophysical surveys have been performed in a woody box $\left(110 \times 110 \times 60 \mathrm{~cm}^{3}\right)$ filled with about $60 \%$ of sand and $40 \%$ of clay (Fig. 1). The soil moisture in the box, measured by thermogravimetry at the start of the experiments, was approximately $10 \%$ of the dry soil weight. For experiment, a three years old peach tree was planted at the centre of the box.

The growth of roots and their distribution in width and depth depend largely on the genetic characteristics of the species, but equally important for morphological development of the roots are the natural characteristics of the soil. The aim of the experiment was to assess the potentiality of GPR and ERT in the identification of the roots; so we decided to use a woody plant with root system of modest growth in order to put ourselves in the most difficult to identify the roots.

\subsection{Ground penetrating radar survey}

A SIR 2000 Radar System with a monostatic antenna of nominal peak frequency equal to $1500 \mathrm{MHz}$ was used to accomplish the survey. The data were acquired in continuous mode with acquisition time range of $6.0 \mathrm{~ns}$ along $0.05 \mathrm{~m}$. spaced survey lines, using 512 samples per trace. A total of 15 parallel profiles were made to obtain a 3-D representation of the scene.

The GPR data set was processed by the REFLEX- Win Version 5.0.5 program (Sandmeier, 2001). Standard data processing had the aim of improving the "imaging" by correctly locating and focussing all the reflectors and was performed through different steps. The first step was the trace removal to eliminate the ends of the radargrams when the antenna 

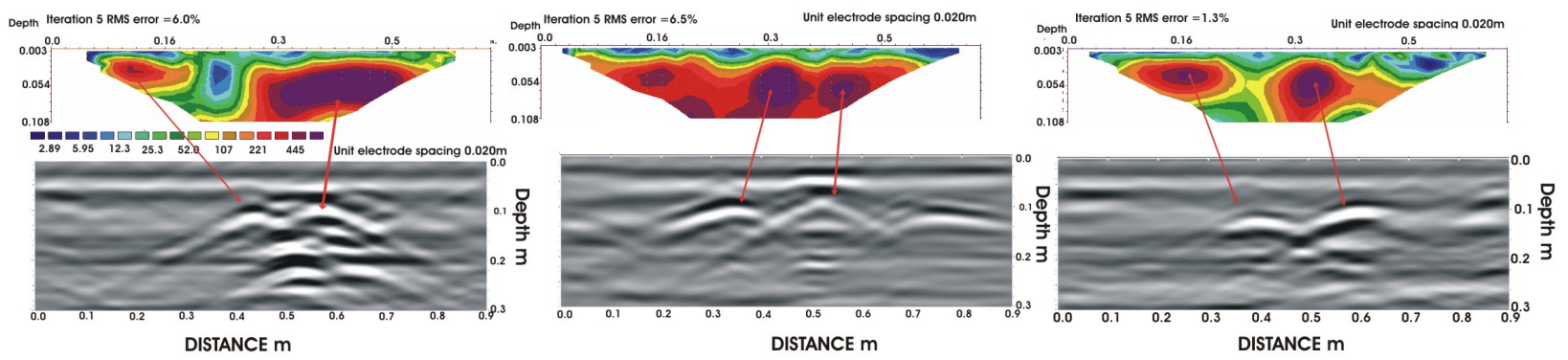

Fig. 2. Comparing some significant ERT (above) and GPR (below) sections. The images show relevant results in correspondence of the root zone, in terms of resistivity anomalies and hyperbolic reflectors.

was not dragged. Then, a zero time correction removed the propagation path of the signal within the cable and antenna. The third step was the gain removal and the energy decay compensation with the aim of restoring the correct amplitude along each wavelet. A band-pass frequency filter with cutoff frequencies was set to reduce the noise at high and low frequencies. Subsequently, the background removal eliminated all the reflections that are not spatially varying along the direction of antenna's movement; in this way the contribution of the air/soil and buried interfaces was erased. Finally, an envelope function was needed to show the results in terms of instantaneous amplitude of the processed signal.

\subsection{Electrical resistivity tomography survey}

To complete and integrate the GPR data, electrical resistivity tomography (ERT) was performed to obtain high-resolution electrical images of the subsurface occupied by tree roots. Two-dimensional electrical resistance images of the roots of the peach tree have been carried out using the IRIS Georesistivimeter R2 with multi-electrode acquisition system in a Wenner-Schlumberger array configuration where the electrodes spacing on the surface is of $0.02 \mathrm{~m}$.

We exploited the method proposed by Loke and Barker (1996) to process the data and thus transform the apparent resistivity pseudosection into a model of the subsurface resistivity distribution. The inversion routine is based on the smoothness-constrained, least squares inversion of Sasaki (1992) implemented with a quasi-Newton optimization technique. The subsurface is subdivided into rectangular blocks whose number is related to the measuring points. The optimization method iteratively adjusts the 2-D resistivity model to perform the minimization of a cost function accounting for the misfit between the theoretically evaluated apparent resistivity values and the measured ones.

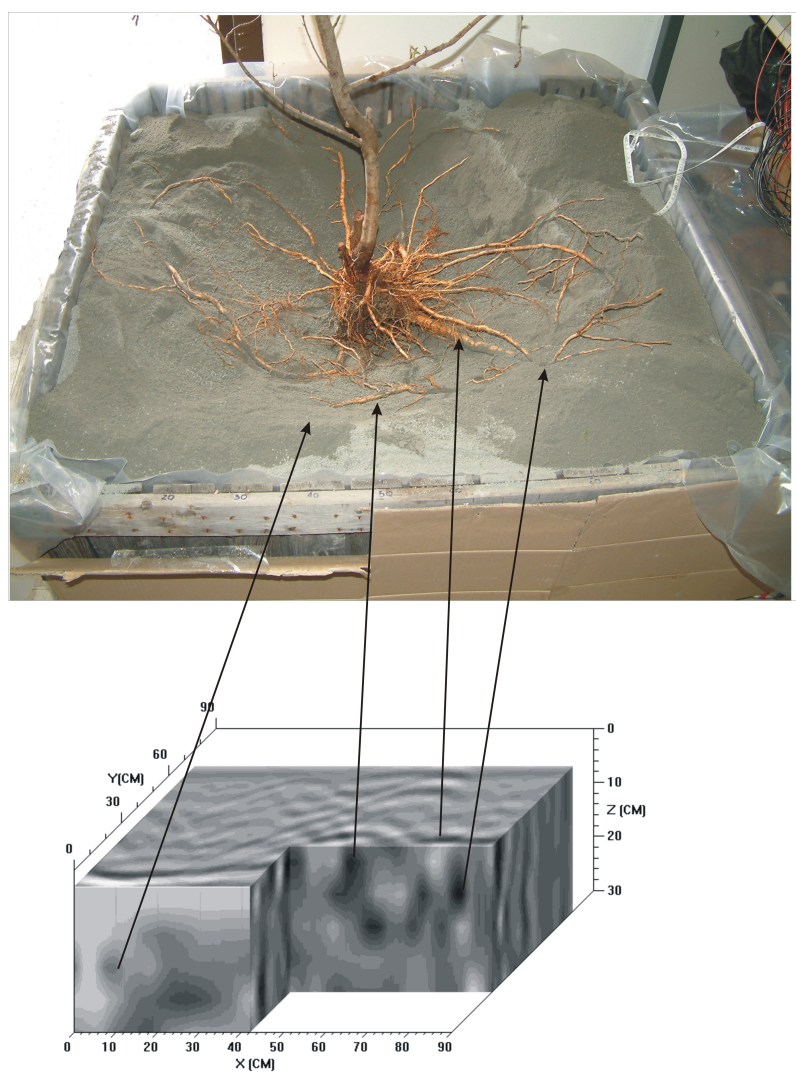

Fig. 3. Three-dimensional GPR image (1500 MHz) for data collected along profiles parallel in woody box filled with clay and sand. The 3-D block reflects the root zone below the tree trunk, arrows indicate some sections of roots clearly visible. The depth of investigation was $30 \mathrm{~cm}$.

\section{Laboratory experiment results}

The results of GPR and ERT surveys are shown in Figs. 2 and 3.

In particular, Fig. 2 reports the most relevant radargrams and the respective geoelectric profiles that were superimposed on the same corresponding GPR sections. 
Depending on the size of the box, the radargram are $90 \mathrm{~cm}$ long; they are characterized by many hyperbolic reflectors determined by the presence of types of roots along the soil profile.

The geoelectrical resistivity images obtained by ERT, on the basis of the resistivity values and size of resistivity anomalies, are enough to distinguish between old and dry woody roots of high resistivity and the network of young, active and hydraulically conductive fine roots with a low electrical resistivity. Then, as seen from Fig. 2, the integration of the two techniques makes easier and more accurate interpretation of the results obtained from surveys carried out.

Multiple two-dimensional GPR sections of data collected have been used to construct a three-dimensional block with the help of Slicer Dicer software (Pixotec, LLC, USA). This enables to reconstruct an accurate three-dimensional image of the spatial volume surveyed to improve the interpretation of the roots structures. Figure 3 depicts a good three dimensional display where it is easier to identify and isolate tree roots in the complexity of the root system itself. The depth of investigation was $30 \mathrm{~cm}$, corresponding to spatial volume occupied by roots of peach tree planted in the box.

\section{Conclusions}

The paper presents an experiment in which two geophysical techniques have been used, the combined application of geophysical methods for mapping tree roots and detecting woody and fine roots is a valid non-invasive tool to be used in the exploration of the subsoil in areas with suspected damage to buildings or monuments because of the near tree roots.

On the basis of the preliminary laboratory results here presented, the next step should be to perform geophysical surveys in urban areas to test the validity of the two geophysical techniques in the identification of the tree roots growth close to buildings and to identify if the roots are potential causes of damage to buildings.

Edited by: L. Eppelbaum, N. Masini, and F. Soldovieri Reviewed by: two anonymous referees

\section{References}

Biddle, P. G.: Tree root damage to buildings, 1, Causes, diagnosis and remedy, Willowmead Publishing, Oxford, UK, 376 pp., 1998.

Blindow, B. N., Erzenginger, P., Pahls, H., Scholz, H., and Tyssen, F.: Continuous profiling of subsurface structures and groundwater surface by EMR methods in Southern Egypt, Berliner Geowiss. Abh. (A), 75 2, 575-627, 1987.
Butnor, J. R., Doolittle, J. A., Kress, L., Cohen, S., and Johnsen K. H.: Use of ground-penetrating radar to study tree roots in the southeastern United States, Tree Physiol., 21, 1269-1278, 2001.

Butnor, J. R., Doolittle, J. A., Johnsen, K. H., Samuelson, L., Stokes, T. and Kress, L.: Utility of Ground-Penetrating Radar as a Root Biomass Survey Tool in Forest Systems, Soil Science Society of American Journal, 67, 1607-1615, 2003.

Caneva, G., Galotta, G., Cancellieri, and Savo, L. V.,Tree roots and damages in the Jewish catacombs of Villa Torlonia (Roma), J Cult. Herit., 10, 53-62, 2009.

Cermak, J., Hruska, J., Martinkova, M., and Prax, A.: urban tree root system and their survival near houses analysed using groun penetrating radar and sap flow techniques, Plant Soil, 219, 103116, 2000.

Daniels, D. J.: Subsurface-penetrating radar, The Institution of Electrical Engineers, London, 300 pp., 1996.

Davis, J. L. and Annan, A. P.: Ground Penetrating Radar for high resolution mapping of soil and rock stratigraphy, Geophys. Prospect., 37, 531-551, 1989.

Driscoll, R.: The influence of vegetation on the swelling and shrinking of clay soils in Britain, Geotechnique, 33, 93-105, 1983.

Hagrey, S. A. al. and Michaelsen, J.: Hydrogeophysical soil study at a drip irrigated orchard, Portugal, Eur. J. Environ. Eng. Geophys., 7, 75-93, 2002.

Hagrey, S. A. al., Meissner, R., Werban, U., Ismaeil, A., and Rabbel, W.: HydroBio-Geophyics, The Leading Edge, 23, 670 674, 2004.

Hagrey, S. A. al.: Electrical resistivity imaging of woody tree trunks, Near Surf. Geophys., 4, 177-185, 2006.

Hruška, J., Cermák, J., and Sustek, S.: Mapping of tree root systems by means of the ground penetrating radar, Tree Physiol., 19, 125130, 1999.

Loke, M. H. and Barker, R. D.: Practical techniques for 3-D resistivity surveys and data inversion, Geophys. Prospect., 44, 499$524,1996$.

Loperte, A., Cristallo, F., Lapenna, V., Bavusi, M., Piscitelli, S., and Rizzo, E.: GPR and Electrical tomography survey to detect cavities in the urban area of Matera (Southern Italy), Progress in Electromagnetic Research Symposium, 28-31 March 2004, Pisa, Italy, 2004.

Morey, R. M.: Continuous subsurface profiling by impulse radar, Proceedings of Conference on Subsurface Exploration for Underground Excavation and Heavy Construction, Am. Soc. Of Civil Engineers, Henniker, NH, 213-232, 1974.

Navarro, V., Candel, M., Yustres, Alonso, Á. J., and Garcí, B.: Trees, lateral shrinkage and building damage, Eng. Geol., 108, 189-198, 2009.

Navarro, V., Candel, M., Yustres, J., and Alonso, Á.J., Trees, soil moisture and foundation movements, Comput. Geotech.m 36, 810-818, 2009.

Piscitelli, S., Rizzo, E., Cristallo, F., Lapenna, V., Crocco, L., and Soldovieri, F., GPR and microwave tomography for detecting shallow cavities in the historical area of "Sassi of Matera" (southern Italy), Near Surf. Geophys., 5, 275-284, 2007.

Sandmeier, K. J.: Program for Processing and Interpretation of Reflection and Transmission data, Karlsruha, Germany, 2001.

Sasaki, Y.: Resolution of resistivity tomography inferred from numerical simulation, Geophys. Prospect., 40, 453-64, 1992.

Skaar, C.: Wood-Water Relations, Springer-Verlag, Heidelberg, 
NY, 279 pp., 1988.

Stokes, A., Fourcaud, T., Hruška, J., Cermák, J., Nadezhdina, N., Nadezhdin, V., and Praus, L.: An evaluation of different methods to investigate root system architecture of urban trees in situ, I. Ground-penetrating radar, Journal of Arboriculture, 28, 2-10, 2002.

Ulriksen, P.: Application of impulse Radar to Civil Engineering, Doctoral Thesis, Lund university of Technology, Dept. of Eng. Geol., Sweden. Coden: Lutvdg/(TVTTG-1001)/1-175, 1982.
Weihs, U., Dubbel, V., Krummheuer, F., and Just, A.: The electrical resistivty tomography - A promising technique for detection of coloured heartwood on standing beech trees, Forst und Holz, 54, 166-170, 1999. 